\title{
Comparison of Two Suspension Arrays for Simultaneous Detection of Five Biothreat Bacterial in Powder Samples
}

\author{
Yu Yang, Jing Wang, ${ }^{1}$ Haiyan Wen, ${ }^{2}$ and Hengchuan Liu ${ }^{3}$ \\ ${ }^{1}$ Institute of Health Quarantine, Chinese Academy of Inspection and Quarantine, Beijing 100123, China \\ ${ }^{2}$ Chongqing International Travel Healthcare Center, Chongqing 400020, China \\ ${ }^{3}$ West China School of Public Health, Sichuan University, Chengdu 610041, China
}

Correspondence should be addressed to Jing Wang, wjwjwang@gmail.com

Received 2 December 2011; Accepted 28 February 2012

Academic Editor: Sabah Mohammed

Copyright ( $) 2012$ Yu Yang et al. This is an open access article distributed under the Creative Commons Attribution License, which permits unrestricted use, distribution, and reproduction in any medium, provided the original work is properly cited.

\begin{abstract}
We have developed novel Bio-Plex assays for simultaneous detection of Bacillus anthracis, Yersinia pestis, Brucella spp., Francisella tularensis, and Burkholderia pseudomallei. Universal primers were used to amplify highly conserved region located within the $16 \mathrm{~S}$ rRNA amplicon, followed by hybridized to pathogen-specific probes for identification of these five organisms. The other assay is based on multiplex PCR to simultaneously amplify five species-specific pathogen identification-targeted regions unique to individual pathogen. Both of the two arrays are validated to be flexible and sensitive for simultaneous detection of bioterrorism bacteria. However, universal primer PCR-based array could not identify Bacillus anthracis, Yersinia pestis, and Brucella spp. at the species level because of the high conservation of $16 \mathrm{~S}$ rDNA of the same genus. The two suspension arrays can be utilized to detect Bacillus anthracis sterne spore and Yersinia pestis EV76 from mimic "write powder" samples, they also proved that the suspension array system will be valuable tools for diagnosis of bacterial biothreat agents in environmental samples.
\end{abstract}

\section{Introduction}

The threat of bioterrorism has attracted great attention after the letter containing anthrax spore terrified the USA and the letters with "white powder" flied all over the world [1]. When a bioterrorism attack occurred, rapid detection and identification of biothreat agents are important to determine that the suitable actions should be implemented to disinfect pollution and cure infected people. Now, greater than 160 species of microorganisms have been recognized to be pathogenic. Thirty of them could be used as bioweapons. Bacillus anthracis, Yersinia pestis, Brucella spp., Francisella tularensis, and Burkholderia pseudomallei were the typical examples among the list [2]. The development of rapid, sensitive, and high-throughput diagnostic methods to fight against bioterrorism and prevent serious epidemic diseases is under urgent needs.

With the application of PCR and DNA sequencing technologies, comparison of the genome sequences of bacterial species showed that the $16 \mathrm{~S}$ rDNA gene is highly conserved among individuals of the same species and among species of the same genus and hence can be used as the "gold standard" for classification of bacteria [3-6]. Here, we report a suspension array based on the $16 \mathrm{~S}$ rDNA gene amplified by universal primers, which is also called universal primer PCR-based array. Due to the scope of the detection specificity of our array design principles, the universal primer PCRbased array cannot specifically distinguish certain species from bacteria of the same genus because of the conservation of $16 \mathrm{~S}$ rDNA sequences. Alternatively, a suspension-arraybased multiplex PCR was developed which amplifies speciesspecific regions of above five bioterrorism bacteria. Biotin labeled PCR products were hybridized to corresponding probes coupling on the unique sets of fluorescent beads. The hybridized beads were processed through the Bioplex, which identified the presence of PCR products. The hybridization results of above two Luminex xMAP arrays showed sensitivity from $2.5 \mathrm{fg}$ (Yersinia pestis) to $30 \mathrm{pg}$ (Bacillus anthracis) bacterial DNA. 
TABle 1: The primers and probes for detection of Bacillus anthracis, Francisella tularensis, Yersinia pestis, Brucella spp. and Burkholderia pseudomallei by multiplex PCR suspension arrays.

\begin{tabular}{|c|c|c|c|c|}
\hline Target organism & Name & Sequence $\left(5^{\prime}-3^{\prime}\right)$ & Gene location & Product size \\
\hline \multirow{6}{*}{ Bacillus anthracis } & BA-1-F & TGGACGCATACGAGACATAAT & \multirow{3}{*}{$\operatorname{cap} B$} & \multirow{2}{*}{$430 \mathrm{bp}$} \\
\hline & BA-1-R & TGCTTTAGCGGTAGCAGAGG & & \\
\hline & BA-1-P & GAAGAACGCAGGCTTAGATTGGT & & \multirow{4}{*}{212 bp } \\
\hline & BA-2-F & TTTCATAATCATGGATTTCCCG & \multirow{3}{*}{ chromosome } & \\
\hline & BA-2-R & TTACCCAACATCATCTTCGCA & & \\
\hline & BA-2-P & CTCGCTTTCATCGCATTTCTCCC & & \\
\hline \multirow{3}{*}{ Brucella spp. } & Bru-F & TGGCTCGGTTGCCAATATCAA & \multirow{3}{*}{ BCSP31 } & \multirow{3}{*}{$223 \mathrm{bp}$} \\
\hline & Bru-R & GCGCTTGCCTTTCAGGTCTG & & \\
\hline & Bru-P & TTACGCAGTCAGACGTTGCCTAT & & \\
\hline \multirow{3}{*}{ Francisella tularensis } & FT-F & GGGCAAATCTAGCAGGTCAAG & \multirow{3}{*}{ fopA } & \multirow{3}{*}{$250 \mathrm{bp}$} \\
\hline & FT-R & GCTGTAGTCGCACCATTATCCT & & \\
\hline & Ft-P & TGCTGGTTTAACATGGTTCTTTGG & & \\
\hline \multirow{3}{*}{ Yersinia pestis } & YP-F & ACTCAATGTTGTGACGAGGATG & \multirow{3}{*}{ chromosome } & \multirow{3}{*}{$220 \mathrm{bp}$} \\
\hline & YP-R & TTACTTCTAATGCCATCAGGTAGC & & \\
\hline & Yp-P & AACAGTAAGCATCCAGTCGTTCATA & & \\
\hline \multirow{3}{*}{ Burkholderia pseudomallei } & BP-F & CGATCTCGTCAAGGTGTCGG & & \multirow{3}{*}{$150 \mathrm{bp}$} \\
\hline & BP-R & CCCCAGTTCATCTGATACTTGC & chromosome & \\
\hline & Bp-P & AGGTCAATTTCCCGAACAAGACT & & \\
\hline
\end{tabular}

\section{Materials and Methods}

2.1. Bacterial Strains. Bacteria, strains Bacillus anthracis (170044), Bacillus subtilis (170314), Bacillus cereus (170315), Bacillus megaterium (1700201), Bacillus thuringiensis (8268), Bacillus pumilus (63202), Francisella tularensis (410101), Burkholderia pseudomallei (53001), Brucella abortus (544A), Brucella suis (1330S), Curtobacterium citreum (82-3), Yersinia pseudotuberculosis (12718), Brucella abortus (S19), Brucella suis (S2), Brucella ovis (M5), and Burkholderia mallei (58) were provided by State Key Laboratory of Pathogen and Biosecurity of China. Bacteria strains Bacillus anthracis (sterne), Yersinia pestis (Ev76), Pseudomonas aeruginosa (ATCC15442), Staphylococcus aureus (189), Escherichia coli (44104), Escherichia coli (O157:H7), Vibrio Parahaemolyticus (239), Yersinia kristensenii (ATCC 33638), Yersinia frederiksenii (ATCC 33641), Yersinia intermedia (ATCC 29909), Yersinia rohdei (ATCC 43380), Yersinia bercovieri (ATCC 43970), Yersinia mollaretii (ATCC 43969), and Yersinia enterocolitica (ATCC 9610) were stored in our laboratory.

2.2. DNA Extraction. Y. pestis were cultured on Hottinger's agar (Land bridge, China), Brucella and Vibrio Parahaemolyticus were cultured on TSA medium (Difco), B. anthracis were cultured on DSM sporulation medium (Difco) [7], F. tularensis was cultured on 5\% sheep blood agar. All other reference strains used in this study were cultured on LB medium. Bacterial cells were harvested by centrifugation for $5 \mathrm{~min}$ at $8000 \times \mathrm{g}$ and washed two times with $200 \mu \mathrm{L}$ ddH2O. The cell pellet was resuspended in $200 \mu \mathrm{L}$ ddH2O, boiled for $10 \mathrm{~min}$, then centrifuged at $8000 \times \mathrm{g}$ for $5 \mathrm{~min}$. The supernatants were collected and stored at $-20^{\circ} \mathrm{C}$ for measuring the DNA concentration by spectrophotometer (NanoDrop ND-1000).

2.3. Primer and Probe Design. For multiplex PCR-based array, 6 sets of primer pairs and probes were designed (Table 1). The genome sequences of the Bacillus anthracis, Yersinia pestis, Brucella spp., Francisella tularensis, and Burkholderia pseudomallei were obtained from GenBank. Multiple alignments using ClustalW were performed, and the primer sequences and the probes were designed on genus-specific regions, each consisting of a forward primer, reverse primer, and probe designed to target unique genomic sequences of specific bacterial. The two signatures for detection of Bacillus anthracis used in this multiplex assay were developed. The specificities of the primers and probes were evaluated using the Blastn. For Universal PCR-based array, primers $341 \mathrm{a}, 519 \mathrm{~b}$ were designed to amplify conserved regions of $16 \mathrm{~S}$ rDNA gene for bacterial species (Table 2), probes were designed in the amplification region of PCR, containing a 20 dTTP spacer at $5^{\prime}$ end. Primers and probes were synthesized by Sangon Co. Ltd, China.

2.4. PCR Amplification. The genomic DNA of the reference strains were used as template. Universal PCR reactions were done in $50 \mu \mathrm{L}$ of the master mix (Takara Biotechnology Ltd., Dalian, China). The optimum reaction mixture contained takara premix $25 \mu \mathrm{L}$. $400 \mathrm{pmol}$ of each primer, and $2 \mu \mathrm{L}$ of template DNA. Ultra-pure sterilized water was used for negative control. All reactions were performed in a 9700 PCR machine (ABI Biosystem, USA) with the following cycles: first cycle, $95^{\circ} \mathrm{C}$ for $5 \mathrm{~min} ; 35$ cycles, $95^{\circ} \mathrm{C}$ for $40 \mathrm{~s}, 58^{\circ} \mathrm{C}$ for $30 \mathrm{~s}$, and $72^{\circ} \mathrm{C}$ for $40 \mathrm{~s}$, followed by a final 
TABle 2: The Universal primers and probes for detection of Bacillus anthracis, Francisella tularensis, Yersinia pestis, Brucella spp. and Burkholderia pseudomallei by suspension arrays.

\begin{tabular}{lcc}
\hline Target organism & Name & Sequence $\left(5^{\prime}-3^{\prime}\right)$ \\
\hline 16S rRNA universal primers & $341 \mathrm{a}$ & CCTACGGGAGGCAGCAGT \\
& $519 \mathrm{~b}$ & ATTACCGCGGC(T/G)GCTG \\
Bacillus anthracis & B.a & AAGTGCTAGTTGAATAAGCTGGCAC \\
Brucella spp. & Bru & GGAGAAGATAATGACGGTAACCCGA \\
Francisella tularensis & F.t & GCCTCAAGGTTAATAGCCTTGGGGA \\
Yersinia pestis & Y.p & AAGGGGTTGAGTTTAATACGCTCAA \\
Burkholderia pseudomallei & B.p & AATCATTCTGGCTAATACCCGGAGT \\
\hline
\end{tabular}

extension of $7 \mathrm{~min}$ at $72^{\circ} \mathrm{C}$. Multiplex PCR reactions used the same amplification conditions and the primer and probe sets were first individually tested and then tested in mixtures. The optimal multiplex PCR reagents are the concentration of Taq polymerase, ddNTP, $\mathrm{Mg}^{2+}$ and primers. Not only the multiplex PCR reagents but the PCR annealing temperature, hybridization temperature, hybridization time, and the amount of PCR product were optimized as well.

2.5. Beads Coupling and Hybridization. The probes (Tables 1 and 2) were coupled to carboxylated beads (Luminex) internally dyed with a unique spectral address by modified carbodiimide coupling method [8]. Coupling efficiency was assessed by biotinylated oligonucleotide that was complementary to the probe sequence, the beads were stored in TE buffer ( $\mathrm{pH} 8.0)$ in the dark at $4^{\circ} \mathrm{C}$. Each hybridization reaction in a total volume of $50 \mu \mathrm{L}$ was performed in a 9700 PCR machine (ABI Biosystem, USA) by mixing of $5 \sim 17 \mu \mathrm{L}$ PCR product, $33 \mu \mathrm{L} 1.5 \times$ TMAC $(4.5 \mathrm{M}$ TMAC, $0.15 \%$ Sarkosyl, $75 \mathrm{mM}$ Tris-HCl, $6 \mathrm{mM}$ EDTA) containing 5000 beads of each conjugate, and up to $50 \mu \mathrm{L}$ of TE buffer. The hybridization protocol was as follows: an initial denaturing step of $10 \mathrm{~min}$ at $95^{\circ} \mathrm{C}$, followed by incubation for $15 \mathrm{~min}$ at $55^{\circ} \mathrm{C}$. Then, the reaction system was transferred to a 96-well filter plate (Millipore Corporation, USA), washed two times with $6 \times \operatorname{SSPET}(6 \times$ SSPE, $0.01 \%$ Triton $\mathrm{X}$ $100)$ with vacuum filtration, and incubated for $10 \mathrm{~min}$ at room temperature with $75 \mu \mathrm{L} 4 \mathrm{ng} / \mu \mathrm{L}$ SA-PE (Molecular Probe). Each well was corresponded to one test sample, and the product of PCR negative control was used as hybridization-negative control. The hybridized beads were washed again with $75 \mu \mathrm{L} 1 \times$ TMAC and resuspended in $75 \mu \mathrm{L}$ $1 \times$ TMAC. Data for each sample was collected using a Bioplex workstation (Bio-Rad, USA). For each probe (bead set) in a certain sample well, the MFI value was calculated from the signals of at least 100 beads. The experiment was repeated two to three times for each test sample to confirm the results. A detection threshold value was defined for each probe as two times of average background signal for that probe. Signals above the detection threshold were considered as positive.

2.6. Sensitivity and Specificity of Assays. Tenfold dilution series of Bacillus anthracis Sterne, Francisella tularensis, Yersinia pestis EV76, Brucella spp. M5, and Burkholderia pseudomallei was diluted and used to test the sensitivity of the assay as described above. Reference bacterial strains were chosen to test the specificity of the assay.

2.7. Assessment of Array by Bacterial Strains and "White Powder" Samples. To evaluate the potential use of our assay for the detection of "white powder" sample, tenfold dilution series of fresh culture of $B$. anthracis vaccine strain Sterne spore in DSM (Difco) and Y. pestis vaccine strain EV76 in Hottinger's agar (Land bridge, China) were prepared. $500 \mu \mathrm{L}$ of each dilution was added to $0.1 \mathrm{~g}$ flour (milk powder, corn starch, wheat flour, instant fruit-flavored drink mix powder) with vortexing and incubated for $2 \mathrm{hr}$ at room temperature. The negative control was flour without contamination.

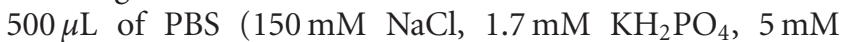
$\mathrm{Na}_{2} \mathrm{PO}_{4}$ (pH7.4)) was added to each sample and vortexed, then centrifuged at $10000 \times \mathrm{g}$ for $3 \mathrm{~min}$, the supernatant was collected and washed with PBS for three times, centrifuged at $12000 \times \mathrm{g}$ for $1 \mathrm{~min}$ each time. DNA extraction, PCR, hybridization, and data analysis were performed as described.

\section{Results and Discussion}

In the work discussed here, we developed two Bio-Plex assays for simultaneous detection of Bacillus anthracis, Yersinia pestis, Brucella spp., Francisella tularensis, and Burkholderia pseudomallei. For universal primer PCR method, the $16 \mathrm{~s}$ rDNA of those five bacterial was amplified, then the PCR products were hybridized with encoded beads labeled by specific $16 \mathrm{~s}$ rDNA probe of each pathogen. Whereas multiplex PCR method was developed to simultaneously amplify multiple specific genes of different pathogens in a single tube, then the PCR products were hybridized with encoded beads labeled by specific probe against target gene. The results were compared between the universal primer PCR and multiplex PCR method.

3.1. Optimization of PCR Amplification. In this assay, $16 \mathrm{~s}$ rDNA was amplified by the average size of $250 \mathrm{bp}$ as Figure 1 indicated the gel electrophoresis with universal primer PCR amplification. The multiplex PCR factors have been optimized to approach the best reaction condition. The optimum reaction mixture contained $30 \mu \mathrm{L}$ of of the 


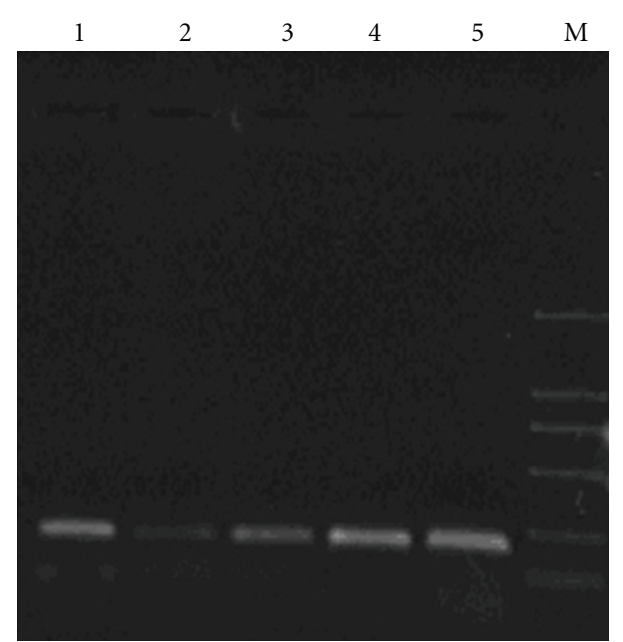

Figure 1: Gel electrophoresis (1\% agarose gel) of the amplification products by universal primers PCR. Lane 1. Francisella tularensis; Lane 2. Burkholderia pseudomallei; Lane 3. Yersinia pestis EV76; Lane 4. Brucella spp. M5; Lane 5. Bacillus anthracis Sterne; M: DL2000 DNA Marker.

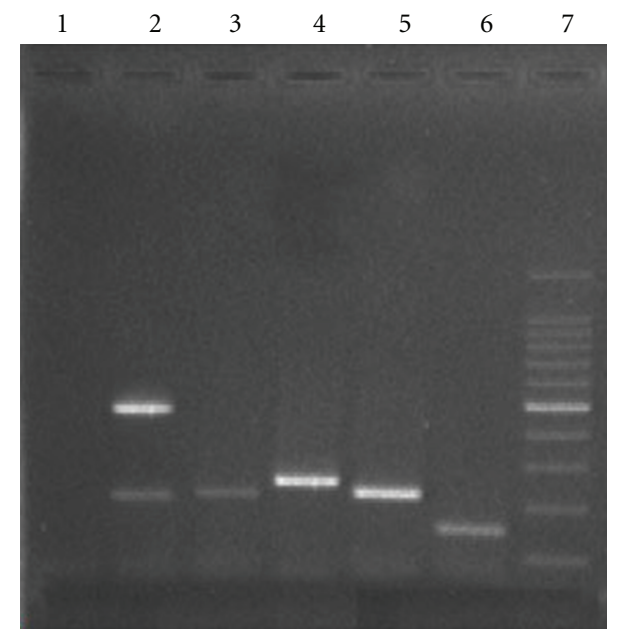

FIGURE 2: Gel electrophoresis (1\% agarose gel) of the amplification products by multiplex PCR Lane 1.blank; Lane 2. Bacillus anthracis Sterne; Lane 3. Yersinia pestis EV76; Lane 4. Francisella tularensis; Lane 5. Brucella spp. M5; Lane 6. Burkholderia pseudomallei; Lane 7. DL2000 DNA Marker.

master mix, 80 pmol of primer FT-F, FT-R, BP-F, BP-R, BA1-F, BA-1-R, 100 pmol of primer BA-2-F, BA-2-R, YP-F, YP$\mathrm{R}, 120 \mathrm{pmol}$ of primer Bru-F, Bru-R each, $2 \mu \mathrm{L}$ of DNA template. Thermal cycles included 1 cycle of $95^{\circ} \mathrm{C}$ for $10 \mathrm{~min}$, 32 cycles of $95^{\circ} \mathrm{C}$ for $30 \mathrm{~s}, 58^{\circ} \mathrm{C}$ for $30 \mathrm{~s}$, and $72^{\circ} \mathrm{C}$ for $30 \mathrm{~s}$, followed by a final extension of $7 \mathrm{~min}$ at $72^{\circ} \mathrm{C}$. Figure 2 shows the gel electrophoresis the multiplex PCR products.

3.2. Array Sensitivity of Universal Primer PCR Array versus Multiplex PCR Array. The limits of detection for each bacterium were tested in universal primer PCR-based array and multiplex PCR-based array. Figure 3 shows the limits of detection for each set of primers when tested universal primer PCR and multiplex PCR in individual species. We observed that a semilogarithm dose-response curve between the MFI and DNA concentration followed a dynamic range. The universal primer PCR-coupled liquid bead array was capable of detecting the specific target sequence when a minimum amount of $0.8 \mathrm{pg}$ Burkholderia pseudomallei, $40 \mathrm{pg}$ Brucella spp., $14 \mathrm{pg}$ Bacillus anthracis, 0.2 pg Francisella tularensis, or 2.2 pg Yersinia pestis genomic DNA template was present in the PCR amplification reactions; the multiplex PCR-suspension array was sensitive with a detection limit of $0.62 \mathrm{pg}$ Burkholderia pseudomallei, $22.5 \mathrm{pg}$ Brucella spp., $70 \mathrm{pg}$ Bacillus anthracis, $0.95 \mathrm{pg}$ Francisella tularensis, and $50 \mathrm{fg}$ Yersinia pestis genomic DNA template. A negative control was added as previously described [9].

3.3. Array Specificity. Twenty-eight reference strains of certain bacterial species were tested for evaluation of the specificity of the two arrays. Table 3 indicated there are cross reactions existed among the same genus for universal primer PCR-based array. Such as it was positive signals for Bacillus thuringiensis, Bacillus cereus samples using the probes specific to Bacillus anthracis. Whereas there is no false-positive result or cross reactivity observed in multiplex PCR-based assay. Figure 4 shows the specificity of multiplex PCR array in a $3 \mathrm{D}$ axis with a matrix of each combination of four bacteria species by each multiplex array bead. The high MFI column indicated that each bead was only positive to its corresponding bacterium but not the other four bacteria.

\subsection{Detectability from Cultures and White Powder Mixture.} As shown in Figure 5, we identified B. anthracis spore, and Yersinia pestis EV76 in simulated "white powder", 10000 cells $/ 0.1 \mathrm{~g}$ powder of B. anthracis spore and $500 \mathrm{cfu} / 0.1 \mathrm{~g}$ powder of Yersinia pestis EV76 showed positive signals when tested by both two assays, which are significantly below the median lethal dose (LD50) of 8000 10000 cfu Bacillus anthracis [10] and $3000 \mathrm{cfu}$ Yersinia pestis [11]. The results suggested these two types of arrays have enough detective ability to detect suspect bioterrorism agents from white powders with high sensitivity and good dynamic detection range.

\section{Conclusion}

Dozens of techniques have been developed for detecting and identifying biothreat agents by cell culture, lateral immunological flow, PCR, biosensor, solid- or liquid-based biochip and analytical chemistry (GC and MS, etc.) methods $[9,12,13]$, biochemistry-based techniques, and analytical chemistry method [14-17]. However, detecting potential biological agents in environmental and clinical samples requires assays that can recognize multiple analytes simultaneously to reduce the responding time and minimize the impact of the bioattack. In this study, we have developed a rapid high-throughput suspension array for simultaneous detection of Bacillus anthracis, Yersinia pestis, Brucella spp., Francisella tularensis, and Burkholderia pseudomallei. 


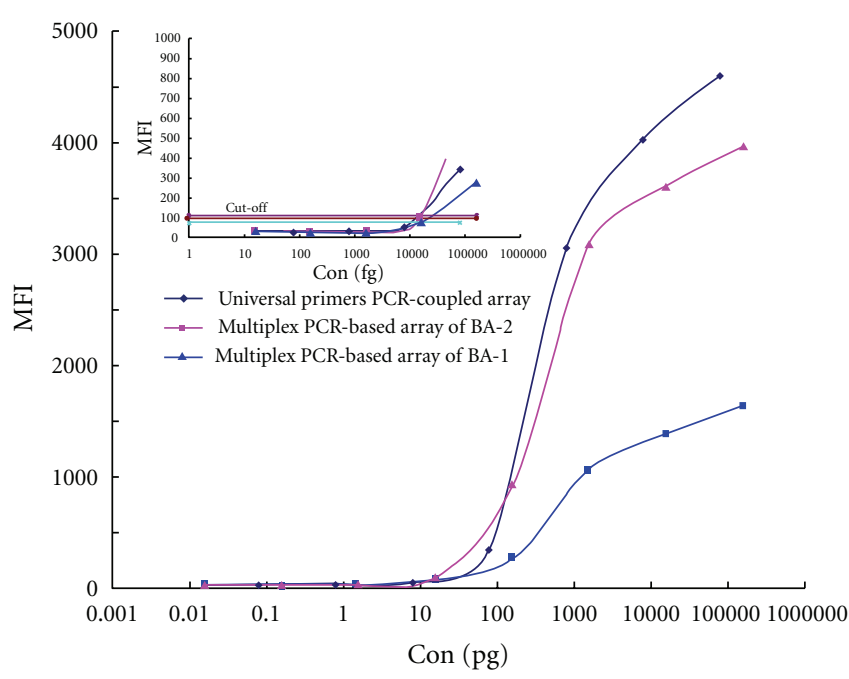

$\rightarrow$ Universal primers PCR-coupled array

$\_$Multiplex PCR-based array of BA-1

$\rightarrow$ Multiplex PCR-based of BA-2

(a)

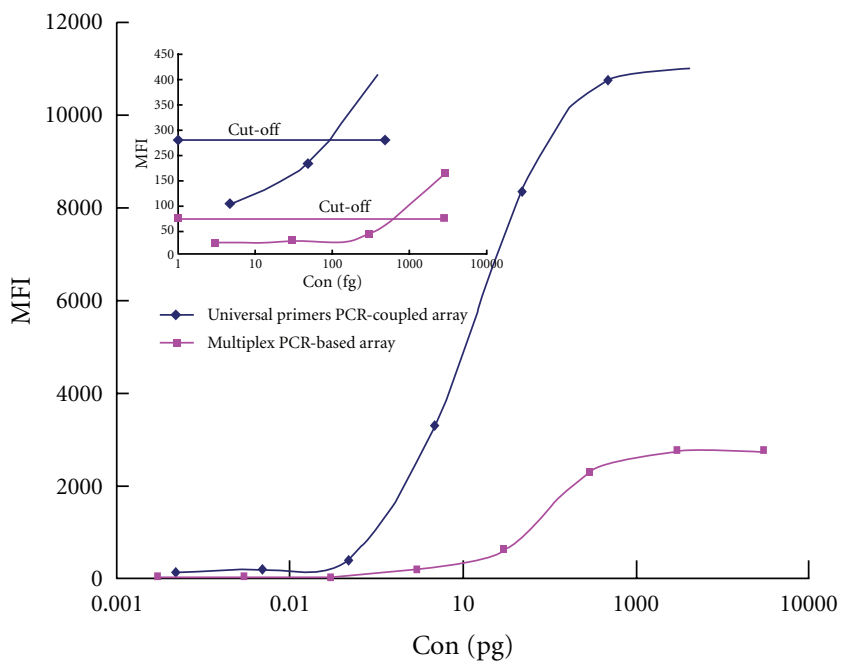

$\rightarrow \quad$ Universal primers PCR-coupled array

$\rightarrow$ Multiplex PCR-based array

(c)

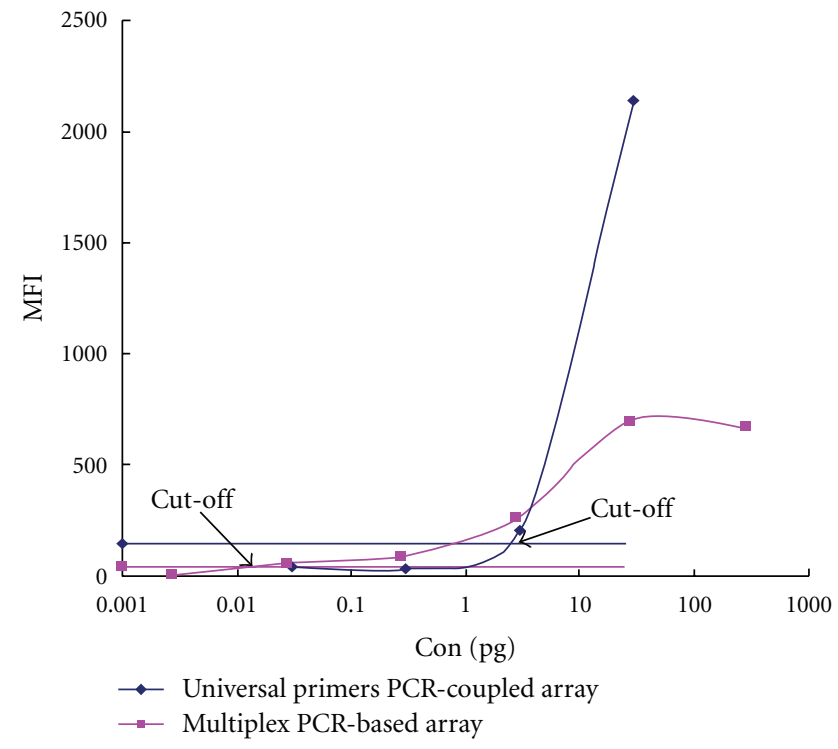

(b)

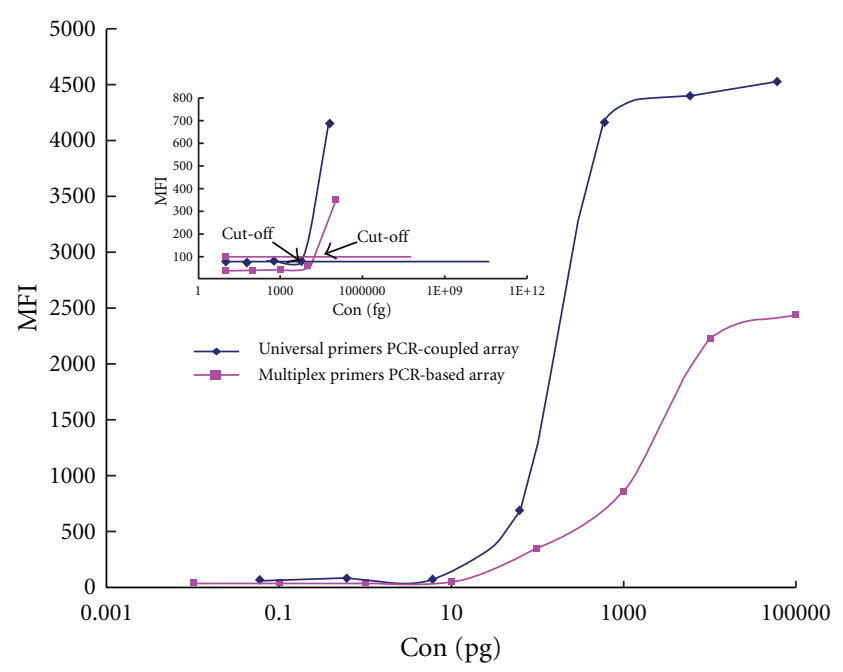

Universal primers PCR-coupled array

॥ Multiplex PCR-based array

(d)

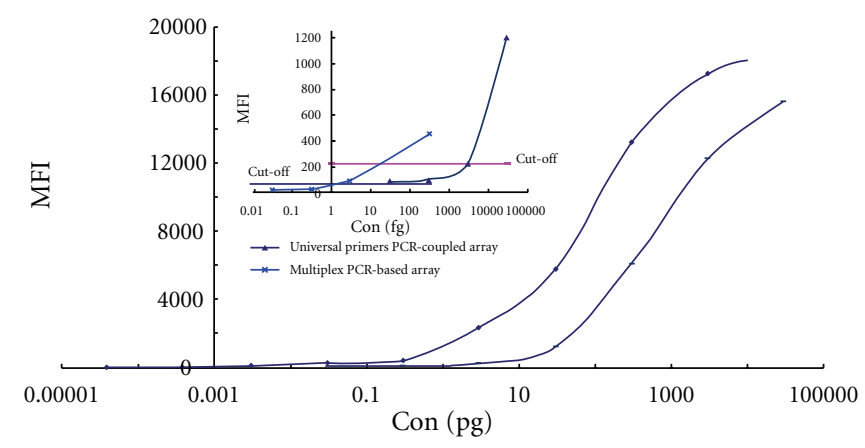

- Multiplex PCR-based array

__ Universal primers PCR-coupled array

(e)

FIgure 3: Comparison of detection sensitivity of multiplex PCR-based and universal primers PCR-coupled assay, the inlet shows the cut-off value of two assays. (a) Bacillus anthracis; (b) Yersinia pestis; (c) Francisella tularensis; (d) Brucella spp.; (e) Burkholderia pseudomallei. 


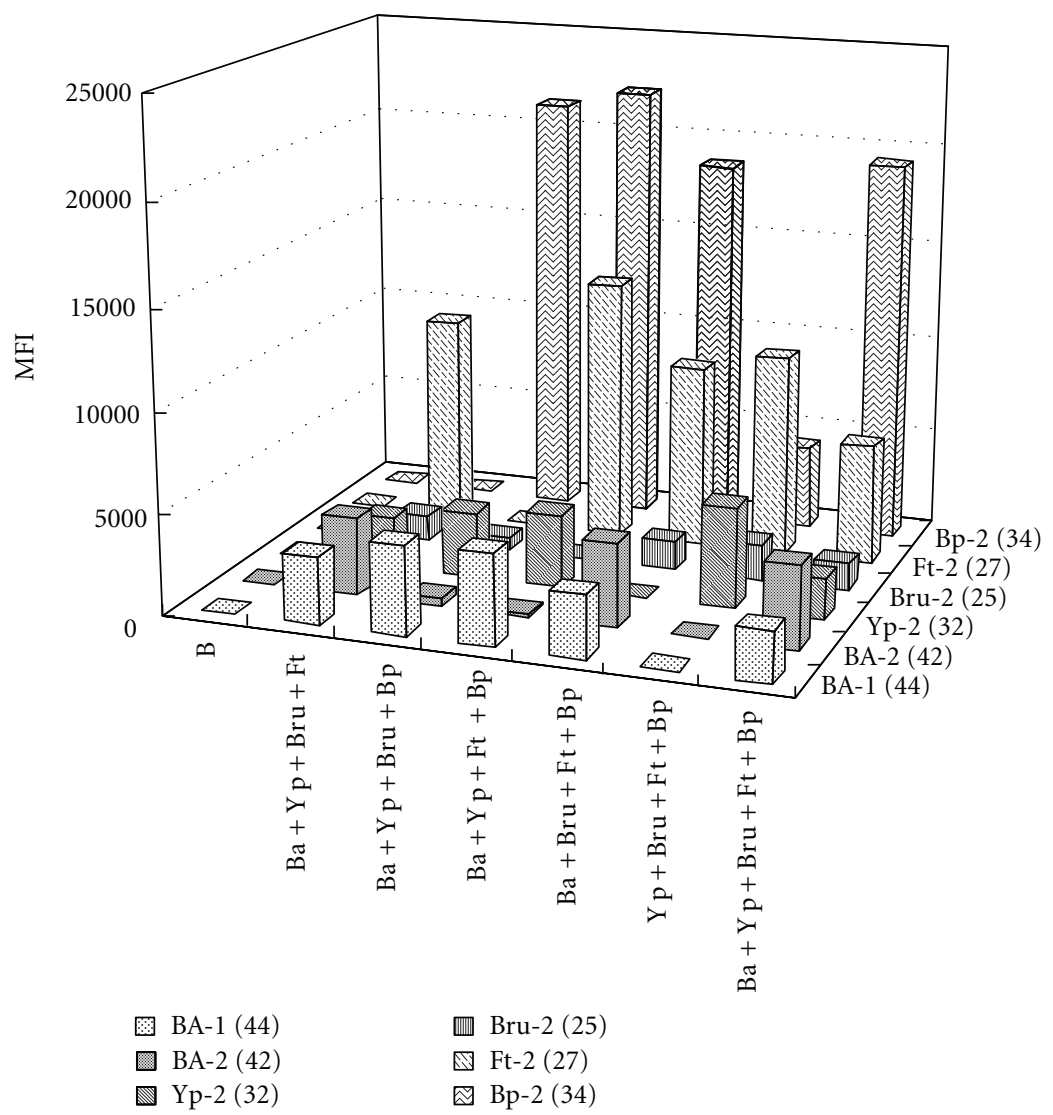

FIGURE 4: Specificity test of probes in multiplex primer PCR-coupled suspension array. For each tested agent ( $x$-axis), the response of each of six beads is shown ( $y$-axis). Response is given as the median fluorescent intensity (MFI) at $z$-axis. Dotted bars indicate the probe of BA1-coated bead; grid bars correspond to BA-2; right-slash bars are Yp-2; straight bars are Bru-2; right-dot bars indicate Ft-2; zigzag bars are $\mathrm{Bp}$-2. From the $y$-axis, B is the blank blocks; $\mathrm{Ba}$ is Bacillus anthracis Sterne; Yp is Yersinia pestis EV76; Bru is Brucella spp. M5; Ft is Francisella tularensis and Bp is Burkholderia pseudomallei. The six bacterial coated beads are from species Bacillus anthracis, Yersinia pestis, Brucella abortus, Francisella tularensis, and Burkholderia pseudomallei, respectively. Each sample yields an appropriate response from each of the six beads present.

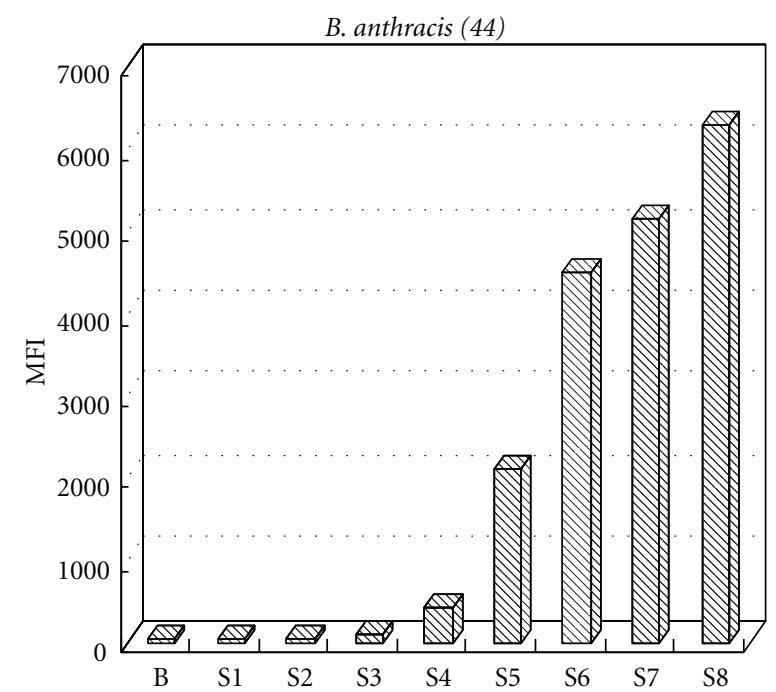

(a)

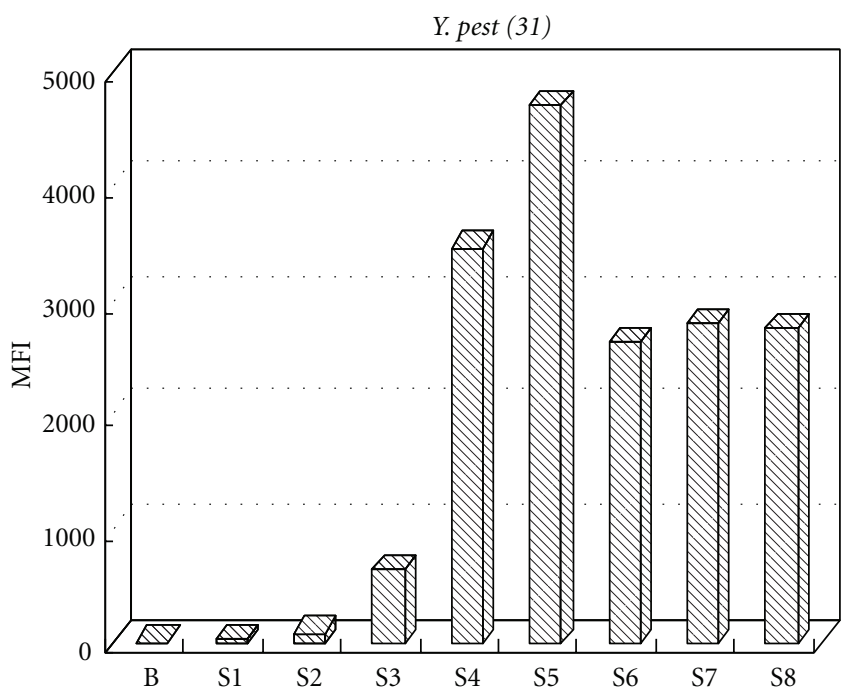

(b)

Figure 5: Detectability for white powder mixture. (a) Bacillus anthracis sterne spore $10^{2} \sim 10^{9}$ cells $/ 0.1 \mathrm{~g}$ detected in white powder. (b) Yersinia pestis Ev76 $5 \times 10^{1} \sim 5 \times 10^{8} \mathrm{cfu} / 0.1 \mathrm{~g}$ detected in white powder. 
TABLE 3: Specificity test of universal primer PCR-coupled suspension array.

\begin{tabular}{|c|c|c|c|c|c|c|c|}
\hline Species & Strain & Brucella Spp. & $\begin{array}{c}\text { Bacillus } \\
\text { anthracis }\end{array}$ & $\begin{array}{c}\text { Francisella } \\
\text { tularensis }\end{array}$ & Yersinia pestis & $\begin{array}{l}\text { Burkholderia } \\
\text { pseudomallei }\end{array}$ & BSA \\
\hline Bacillus anthracis & 170044 & - & + & - & - & - & - \\
\hline Bacillus subtilis & 170314 & - & - & - & - & - & - \\
\hline Bacillus cereus & 170315 & - & + & - & - & - & - \\
\hline Bacillus megaterium & 1700201 & - & - & - & - & - & - \\
\hline Bacillus thuringiensis & $82-68$ & - & + & - & - & - & - \\
\hline Bacillus pumilus & 63202 & - & - & - & - & - & - \\
\hline Francisella tularensis & 410101 & - & - & + & - & - & - \\
\hline $\begin{array}{l}\text { Burkholderia } \\
\text { pseudomallei }\end{array}$ & 53001 & - & - & - & - & + & - \\
\hline Brucella abortus & $544 A$ & + & - & - & - & - & - \\
\hline Brucella suis & $1330 S$ & + & - & - & - & - & - \\
\hline $\begin{array}{l}\text { Curtobacterium } \\
\text { citreum }\end{array}$ & $82-3$ & - & - & - & - & - & - \\
\hline $\begin{array}{l}\text { Yersinia } \\
\text { pseudotuberculosis }\end{array}$ & 12718 & - & - & - & + & - & - \\
\hline Brucella abortus & $S 19$ & + & - & - & - & - & - \\
\hline Brucella suis & S2 & + & - & - & - & - & - \\
\hline Brucella ovis & M5 & - & - & - & - & - & - \\
\hline Burkholderia mallei & 58 & - & - & - & - & + & - \\
\hline Bacillus anthracis & sterne & - & + & - & - & - & - \\
\hline Yersinia pestis & Ev76 & - & - & - & + & - & - \\
\hline $\begin{array}{l}\text { Pseudomonas } \\
\text { aeruginosa }\end{array}$ & ATCC15442 & - & - & - & - & - & - \\
\hline Staphylococcus aureus & 189 & - & - & - & - & - & - \\
\hline Escherichia coli & 44104 & - & - & - & - & - & - \\
\hline Escherichia coli & O157:H7 & - & - & - & - & - & - \\
\hline $\begin{array}{l}\text { Vibrio } \\
\text { Parahaemolyticus }\end{array}$ & 239 & - & - & - & - & - & - \\
\hline Yersinia kristensenii & ATCC 33638 & - & - & - & - & - & - \\
\hline Yersinia frederiksenii & ATCC 33641 & - & - & - & + & - & - \\
\hline Yersinia intermedia & ATCC 29909 & - & - & - & - & - & - \\
\hline Yersinia rohdei & ATCC 43380 & - & - & - & - & - & - \\
\hline Yersinia bercovieri & ATCC 43970 & - & - & - & - & - & - \\
\hline Yersinia mollaretii & ATCC 43969 & - & - & - & - & - & - \\
\hline Yersinia enterocolitica & АТCC 9610 & - & - & - & - & - & - \\
\hline
\end{tabular}

The highly conserved 16S rRNA gene makes a remarkable role in analysis of evolutionary distance and relatedness of organisms and has a widespread use for bacterial identification and taxonomy determination. The results from $16 \mathrm{~s}$ rRNA universal primer PCR-based suspension array suggested that this method could be used to detect almost all of the bacterial. However, it should be noted that this method could not identify bacterial species with highly conserved $16 \mathrm{~s}$ rDNA sequence. In our study, Bacillus anthracis, Bacillus thuringiensis, and Bacillus cereus belong to same genus, which has $99 \%$ identity of $16 \mathrm{~s}$ rDNA [18]. The results also showed high positive signals for Bacillus thuringiensis, Bacillus cereus samples using the probes specific to Bacillus anthracis. The similar results were also observed for
Yersinia pestis and Brucella spp. It suggested that the universal primer PCR-based suspension array could not be used to determine different bacteria in the same genus. In an effort to distinguish five bioterrorism bacteria specific to species as list above, we conducted multiplex PCR to target on unique genomic sequence of specific pathogen in a same suspension array. Those signature primers target on different genomic regions of the pathogen, increased the specificity of an array, and reduced the risk of false-positive results. Two detectable targets of $B$. anthracis, signature gene on the bacteria genome and $c a p B$ gene [19] located on plasmid $\mathrm{pXO} 2$, were chosen, as the $\mathrm{pXO} 2$ plasmid is important to the virulence of B. anthracis. Brucella spp. target in BCSP31 gene [20], Francisella tularensis target in fopA gene [21], 
the detection targets in chromosome of $Y$. pestis [22] and Burkholderia pseudomallei [23] were both specific on the genome. However, not as universal primer PCR-based array, we could not continuously increase signature targets in the multiplex PCR-based suspension array system due to the increased complexity of multiplexed reaction.

Powders were one of the most common nonclinical specimens submitted to designated laboratories. Artificially contaminated samples were prepared as simulated field samples to access the feasibility of the assay established above. In this study, we developed two suspension array methods for rapid detection of Bacillus anthracis, Yersinia pestis, Brucella spp., Francisella tularensis, and Burkholderia pseudomallei. with good sensitivity and specificity, which significantly reduces the detection time due to simultaneous detection of five pathogens. The results suggest the feasibility of using suspension array system in biological weapons diagnosis for environmental samples.

\section{Acknowledgments}

This work was supported by Grant 30900053 from National Natural Science Foundation of China, Grant 2006BAK10B07 from the National Key Technology R\&D Program of China, Grant 2007GYJ023 from the Public Walfare Program of China, and Grant 2009JK027 from CAIQ Foundation. The authors would like to acknowledge Dr. Yang Ruifu, Duan Qing, Song Yajun, Zai Junhui, and Guo Zhaobiao for helpful assistance and suggestions.

\section{References}

[1] J. L. Mothershead, K. Tonat, and K. L. Koenig, "Bioterrorism preparedness III: state and federal programs and response," Emergency Medicine Clinics of North America, vol. 20, no. 2, pp. 477-500, 2002.

[2] D. V. Lim, J. M. Simpson, E. A. Kearns, and M. F. Kramer, "Current and developing technologies for monitoring agents of bioterrorism and biowarfare," Clinical Microbiology Reviews, vol. 18, no. 4, pp. 583-607, 2005.

[3] J. E. Clarridge Jr., "Impact of $16 \mathrm{~S}$ rRNA gene sequence analysis for identification of bacteria on clinical microbiology and infectious diseases," Clinical Microbiology Reviews, vol. 17, no. 4, pp. 840-862, 2004.

[4] S. K. P. Lau, P. C. Y. Woo, and B. Y. L. Chan, "Haemophilus segnis polymicrobial and monomicrobial bacteraemia identified by $16 \mathrm{~S}$ ribosomal RNA gene sequencing," Journal of Medical Microbiology, vol. 51, no. 8, pp. 635-640, 2002.

[5] K. Nakanaga, N. Ishii, K. Suzuki et al., "'Mycobacterium ulcerans subsp. shinshuense' isolated from a skin ulcer lesion: identification based on 16S rRNA gene sequencing," Journal of Clinical Microbiology, vol. 45, no. 11, pp. 3840-3843, 2007.

[6] P. C. Y. Woo, A. M. Y. Fung, S. K. P. Lau, and K. Y. Yuen, "Identification by $16 \mathrm{~S}$ rRNA gene sequencing of Lactobacillus salivarius bacteremic cholecystitis," Journal of Clinical Microbiology, vol. 40, no. 1, pp. 265-267, 2002.

[7] E. M. Lai, N. D. Phadke, M. T. Kachman et al., "Proteomic analysis of the spore coats of Bacillus subtilis and Bacillus anthracis," Journal of Bacteriology, vol. 185, no. 4, pp. 14431454, 2003.
[8] R. J. Fulton, R. L. McDade, P. L. Smith, and L. J. Kienker, "Advanced multiplexed analysis with the FlowMetrix(TM) system," Clinical Chemistry, vol. 43, no. 9, pp. 1749-1756, 1997.

[9] M. T. McBride, S. Gammon, M. Pitesky et al., "Multiplexed liquid arrays for simultaneous detection of simulants of biological warfare agents," Analytical Chemistry, vol. 75, no. 8, pp. 1924-1930, 2003.

[10] T. J. Cieslak and E. M. Eitzen Jr., "Clinical and epidemiologic principles of anthrax," Emerging Infectious Diseases, vol. 5, no. 4, pp. 552-555, 1999.

[11] W. D. Burrows and S. E. Renner, "Biological warfare agents as threats to potable water," Environmental Health Perspectives, vol. 107, no. 12, pp. 975-984, 1999.

[12] N. M. Cirino, K. A. Musser, and C. Egan, "Multiplex diagnostic platforms for detection of biothreat agents," Expert Review of Molecular Diagnostics, vol. 4, no. 6, pp. 841-857, 2004.

[13] C. Ryu, K. Lee, C. Yoo, W. K. Seong, and H. B. Oh, "Sensitive and rapid quantitative detection of anthrax spores isolated from soil samples by real-time PCR," Microbiology and Immunology, vol. 47, no. 10, pp. 693-699, 2003.

[14] N. Balaban and A. Rasooly, "Analytical chromatography for recovery of small amounts of staphylococcal enterotoxins from food," International Journal of Food Microbiology, vol. 64, no. 1-2, pp. 33-40, 2001.

[15] C. A. Bell, J. R. Uhl, T. L. Hadfield et al., "Detection of Bacillus anthracis DNA by LightCycler PCR," Journal of Clinical Microbiology, vol. 40, no. 8, pp. 2897-2902, 2002.

[16] A. Curry, H. Appleton, and B. Dowsett, "Application of transmission electron microscopy to the clinical study of viral and bacterial infections: present and future," Micron, vol. 37, no. 2, pp. 91-106, 2006.

[17] J. L. Versage, D. D. M. Severin, M. C. Chu, and J. M. Petersen, "Development of a multitarget real-time TaqMan PCR assay for enhanced detection of Francisella tularensis in complex specimens," Journal of Clinical Microbiology, vol. 41, no. 12, pp. 5492-5499, 2003.

[18] E. Helgason, O. A. Qkatad, and D. A. Caugant, "Bacillus anthracis, Bacillus cereus and Bacillus thuringiensis-one species on the basis of genetic evidence," Applied and Environmental Microbiology, vol. 66, no. 6, pp. 2627-2630, 2000.

[19] S. E. J. Bell, J. N. Mackle, and N. M. S. Sirimuthu, "Quantitative surface-enhanced Raman spectroscopy of dipicolinic acid-towards rapid anthrax endospore detection," Analyst, vol. 130, no. 4, pp. 545-549, 2005.

[20] G. M. Matar, I. A. Khneisser, and A. M. Abdelnoor, "Rapid laboratory confirmation of human brucellosis by PCR analysis of a target sequence on the 31-kilodalton Brucella antigen DNA," Journal of Clinical Microbiology, vol. 34, no. 2, pp. 477478, 1996.

[21] C. Abril, H. Nimmervoll, P. Pilo et al., "Rapid diagnosis and quantification of Francisella tularensis in organs of naturally infected common squirrel monkeys (Saimiri sciureus)," Veterinary Microbiology, vol. 127, no. 1-2, pp. 203-208, 2008.

[22] L. Radnedge, S. Gamez-Chin, P. M. Mccready, P. L. Worsham, and G. L. Andersen, "Identification of nucleotide sequences for the specific and rapid detection of Yersinia pestis," Applied and Environmental Microbiology, vol. 67, no. 8, pp. 3759-3762, 2001.

[23] C. Supaprom, D. Wang, C. Leelayuwat et al., "Development of real-time PCR assays and evaluation of their potential use for rapid detection of Burkholderia pseudomallei in clinical blood specimens," Journal of Clinical Microbiology, vol. 45, no. 9, pp. 2894-2901, 2007. 

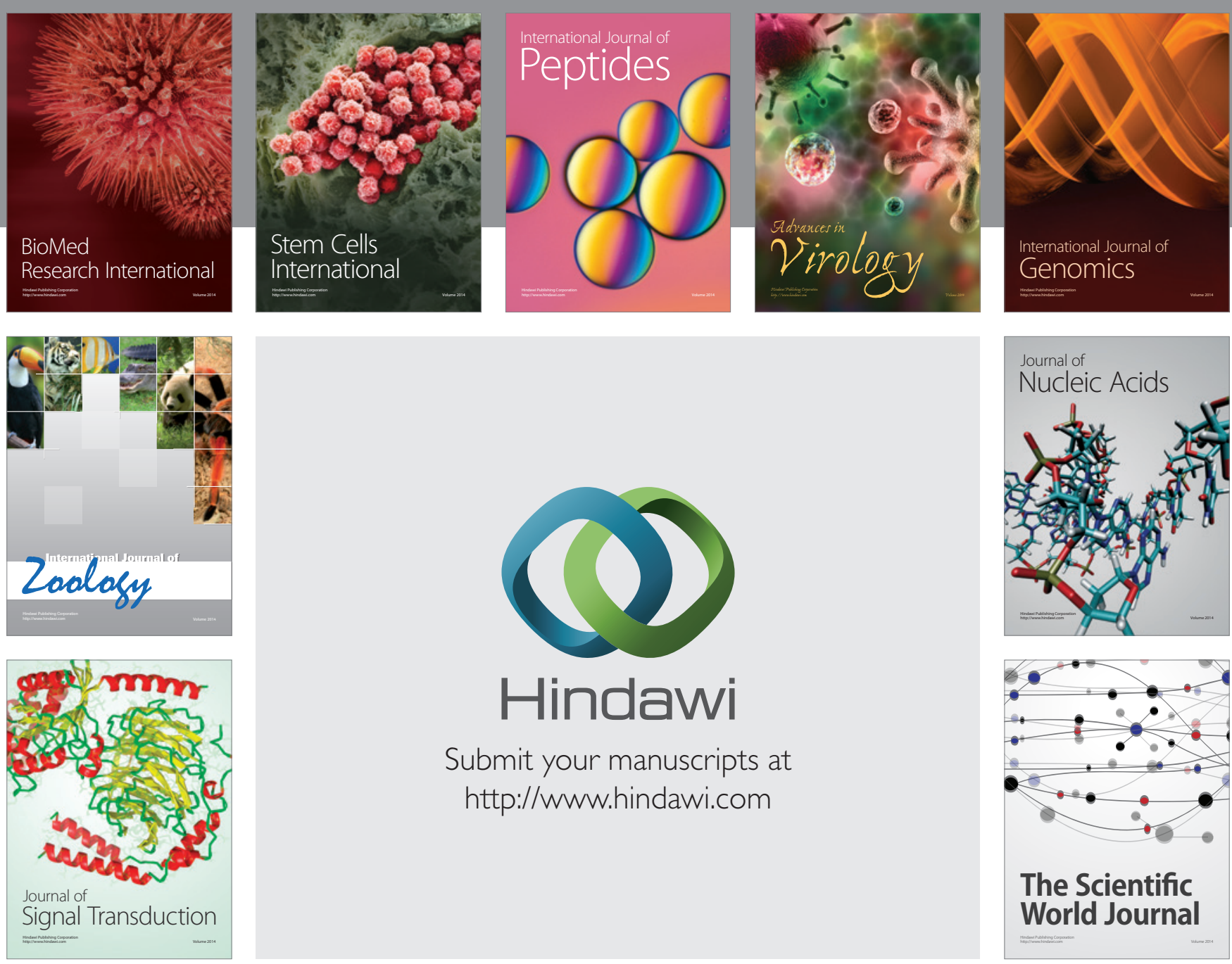

Submit your manuscripts at

http://www.hindawi.com
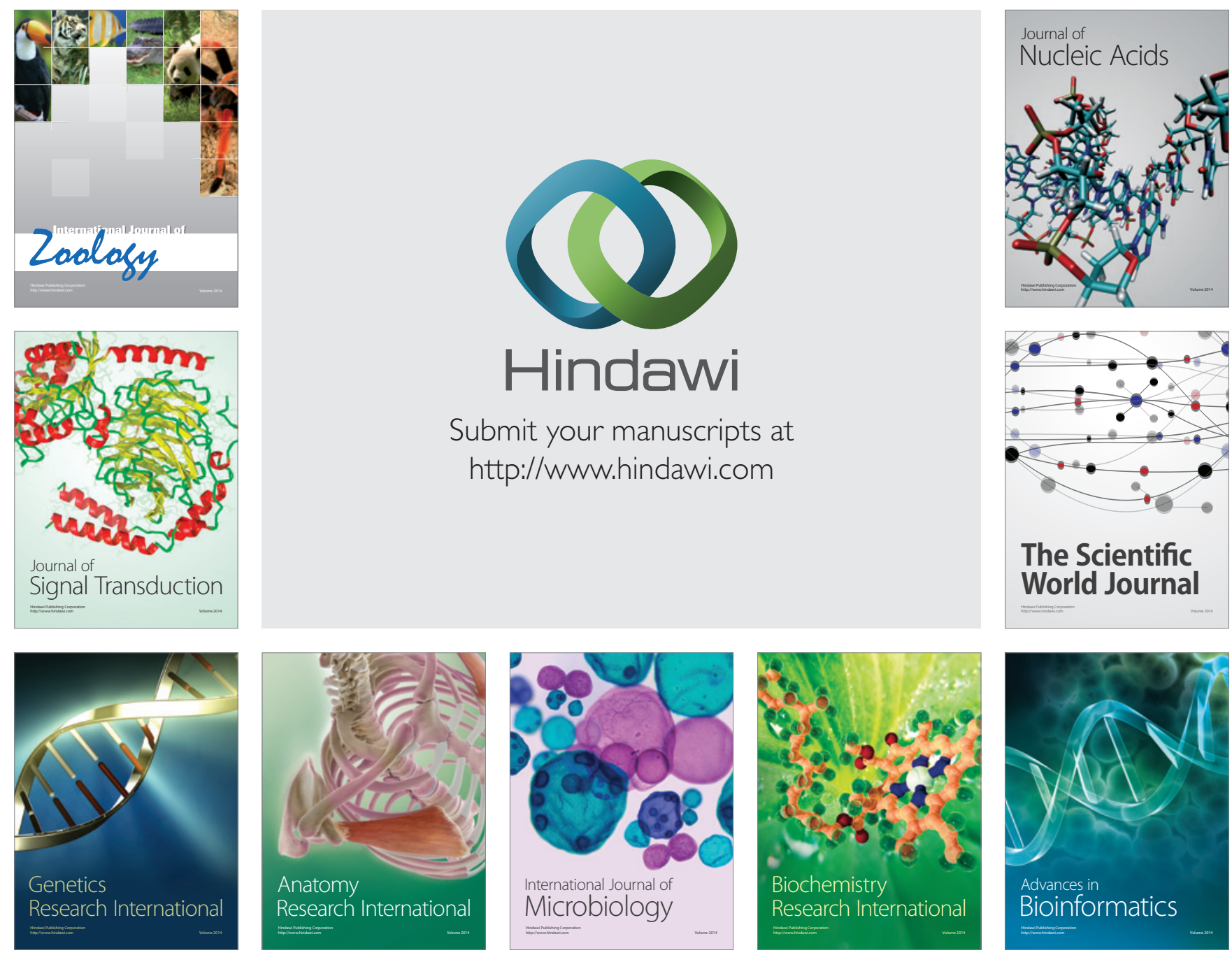

The Scientific World Journal
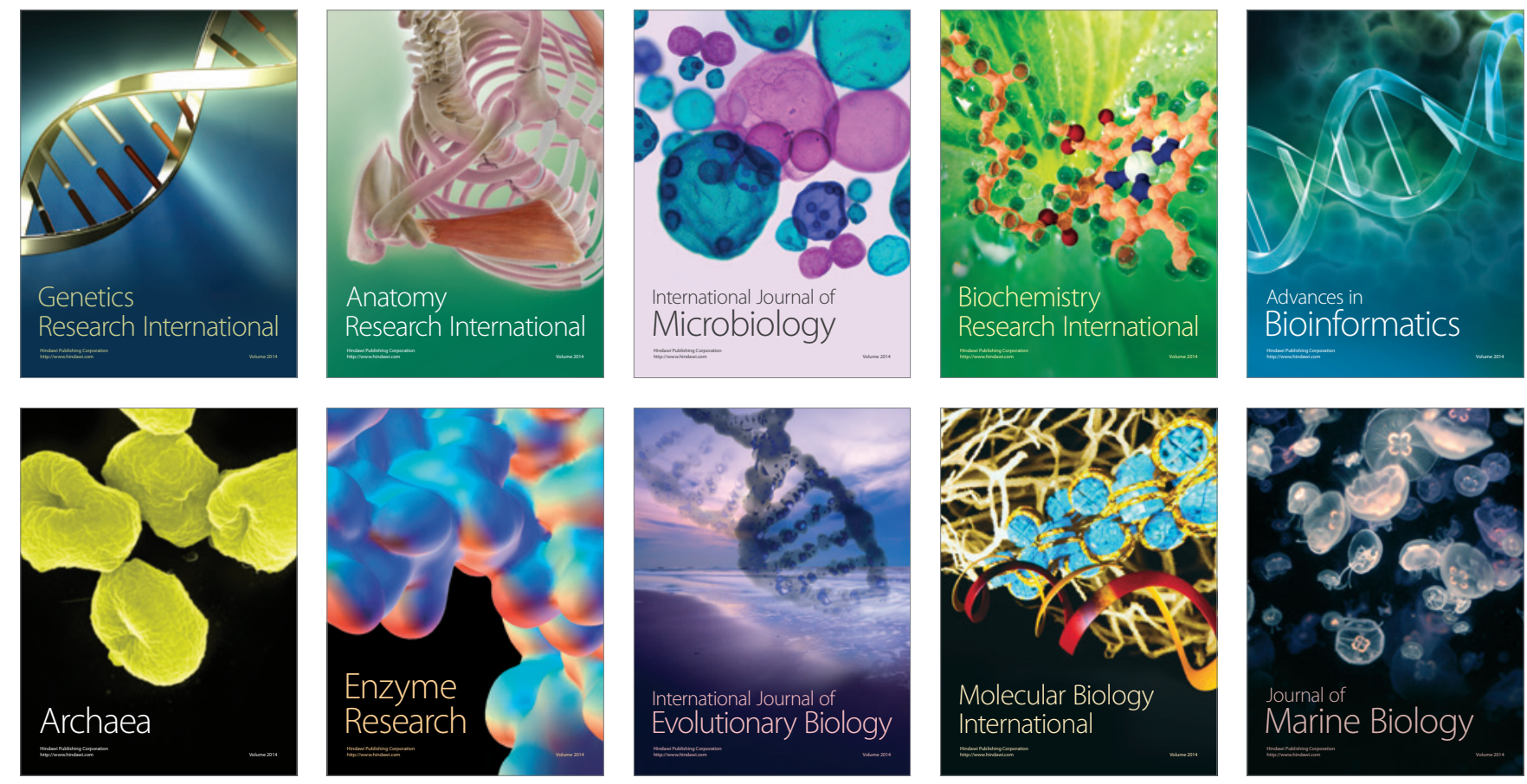